\title{
Tolerance of septoria leaf blotch in winter wheat
}

\author{
S. R. Parker ${ }^{\mathrm{a}} \dagger \ddagger$, S. Welham ${ }^{\mathrm{b}}$, N. D. Paveley ${ }^{\mathrm{a}}$, J. Foulkes ${ }^{\mathrm{c}}$ and R. K. Scott $§$ \\ ${ }^{a}$ ADAS High Mowthorpe, Duggleby, Malton, North Yorkshire Y017 8 BP; ${ }^{\mathrm{b}}$ Rothamsted Research, Harpenden, Hertfordshire AL5 2JQ; and \\ ${ }^{\circ}$ School of Biological Sciences, Division of Agriculture and Horticulture, University of Nottingham, Sutton Bonington Campus, \\ Loughborough, Leicestershire LS12 5RD, UK
}

For individual varieties, tolerance of septoria leaf blotch was quantified by the slope of the relationship between disease and yield. Variation in disease severity and the associated yield responses were provided across two sites and three seasons of field experiments. Slopes were fitted by residual maximum likelihood for two contrasting models: (i) a fixed-effects model, where no prior assumptions were made about the form of the variety slopes; and (ii) a random-effects model, where deviations in individual variety slopes away from the mean variety slope formed a normal random population with unknown variance. The analyses gave broadly similar results, but with some significant differences. The random model was considered more reliable for predicting variety performance. The effects of disease were quantified as symptom area and green canopy duration. Models of the relationship between symptom area and yield were site-specific. When site effects were not taken into account, these models had poor predictive precision. Models based on the canopy green area gave robust predictions of yield and were not site-specific. Differences in disease tolerance were detected in a comparison of 25 commercial winter wheat varieties. Tolerance was not detected directly through symptom measurements, but instead through measurements of canopy green area, which provides a measurement of the effects of disease that accounts for differences in canopy size across sites and seasons. The varieties showing greatest tolerance tended to have lower attainable yield than the intolerant varieties. Presence of the 1BL/1RS chromosome translocation, which has been reported to increase radiation use efficiency, appeared to be associated with intolerance.

Keywords: disease tolerance, Mycosphaerella graminicola REML, residual maximum likelihood, Septoria tritici, wheat yield loss

\section{Introduction}

Disease tolerance is the ability to maintain yield performance in the presence of disease symptoms. Tolerance to foliar disease was first reported more than a century ago by Cobb (1894). However, since that first observation, little progress has been made in quantifying and identifying the traits that confer tolerance. Tolerance is a quantitative trait, expression of which is likely to depend on both genotype and environment. For a limited range of wheat varieties, differences in tolerance to Mycosphaerella graminicola, the cause of septoria leaf blotch, have previously been demonstrated (Ziv \& Eyal, 1978). In one variety of spring wheat, tolerance was shown to be the result of an increase

*To whom correspondence should be addressed.

†E-mail: s.parker@csl.gov.uk

$\ddagger$ Present address: Central Science Laboratory, Sand Hutton, York YO41 1LZ, UK.

\$Deceased.

Accepted 23 September 2003 in the rate of carbon fixation per unit of chlorophyll in leaves infected by S. tritici (Zuckerman et al., 1997). However, conclusive attribution of disease tolerance to specific genotypic differences remains elusive. Reliable quantification of tolerance remains a necessary first step towards identifying traits and genes, or quantitative trait loci, associated with tolerance. Evidence for environmental effects on tolerance has not been demonstrated in wheat.

In winter wheat, the final three leaves capture the majority of photosynthetically active radiation during grain filling (Thorne et al., 1988; Paveley, 1999). This is reflected by the observation that disease severity on the final three leaves is closely correlated to final grain yield (Shaw \& Royle, 1989; Seck et al., 1991). However, the relationship between disease symptoms and yield loss is not consistent across sites, seasons (Bryson et al., 1997; Paveley et al., 1997) and genotypes. A contributory reason for this is that disease yield-loss models often quantify disease on a proportional scale (i.e. as percentage severity; Chiarappa, 1981), which gives no information about crop canopy area and quantifies the spatial and temporal properties of epidemics crudely. Such imprecision in defining these relationships decreases the likelihood of identifying disease 
tolerance. Better progress might be made if yield losses caused by foliar pathogens were analysed in relation to the reduction in photosynthetic area caused by symptom expression (Waggoner \& Berger, 1987; van Oijen, 1990; Spitters et al., 1990).

Differences in disease tolerance can most clearly and simply be quantified where contrasting varieties suffer identical levels of injury (Zadoks \& Schein, 1979). However, this condition is impracticable for comparisons in the field. Variation in disease escape (Lovell et al., 1997), resistance and attainable yield (Nutter et al., 1993) are confounded with variation in tolerance. This problem alone may explain why disease tolerance is not a key breeding objective. Tolerance might alternatively be measured by the slope of the relationship between disease and absolute yield, and thus expressed as yield loss per unit of disease. This test is more practicable because fungicides or crop inoculations can be used to manipulate epidemic severity. These methods inevitably limit the number of variety comparisons, so a priori knowledge of varieties likely to contrast for tolerance is required. In a varietyscreening context this knowledge is unlikely to be available. However, variation in epidemic severity and yield loss might also be obtained by comparisons across sites and seasons.

In variety trials, it has been suggested that predictions from random-effects models will give better predictions of future performance than those based on fixed-effects models because of adjustment for selection bias (Patterson
\& Silvey, 1980). Recently, Cullis et al. (2000) demonstrated that random models used to assess variety yield performance were more reliable and efficient than traditional fixedeffects approaches.

The aim of the work reported here was to test the hypothesis that significant variation in disease tolerance exists within commercial varieties of winter wheat grown in the UK. A secondary aim was to compare the use of random- and fixed-effects models for variety evaluation.

\section{Materials and methods}

\section{Crop agronomy}

Over three crop seasons (1995-97), 25 varieties of winter wheat, variously susceptible to M. graminicola (anamorph, Septoria tritici) were grown in field experiments at two sites in England: ADAS Rosemaund (RM), Hereford and ADAS Starcross (SX), Exeter (Table 1). Both field sites had at least a 1-year break from cereals. All seed was treated with guazatine to suppress fusarium seedling blight, and plots were sown by plot drill in early to mid-October. The experiment was a split-plot design using three replicates, with main plots of either full-fungicide programme to control all disease (Table 2), or untreated. Other pathogens did not develop to threshold levels for treatment, these levels being defined to exclude the other pathogens from the final three leaves in the untreated plots (Table 3). At Starcross in 1997, levels of septoria leaf blotch in

Table 1 Varieties grown in each field experiment and their resistance ratings to Mycosphaerella graminicola

\begin{tabular}{|c|c|c|c|c|c|c|c|}
\hline Variety & Resistance ${ }^{a}$ & SX95 & SX96 & SX97 & RM95 & RM96 & RM97 \\
\hline Admiral & 5 & $\checkmark$ & $\checkmark$ & $\checkmark$ & $\checkmark$ & $\checkmark$ & $\checkmark$ \\
\hline Andante & 7 & $\checkmark$ & $\checkmark$ & $\checkmark$ & $\checkmark$ & $\checkmark$ & $\checkmark$ \\
\hline Avalon & 4 & $\checkmark$ & $\checkmark$ & $\checkmark$ & $\checkmark$ & $\checkmark$ & $\checkmark$ \\
\hline Beaver & 6 & $\checkmark$ & $\checkmark$ & $\checkmark$ & $\checkmark$ & $\checkmark$ & $\checkmark$ \\
\hline Brigadier & 5 & $\checkmark$ & $\checkmark$ & $\checkmark$ & $\checkmark$ & $\checkmark$ & $\checkmark$ \\
\hline Cadenza & 5 & $\checkmark$ & $\checkmark$ & $\checkmark$ & $\checkmark$ & $\checkmark$ & $\checkmark$ \\
\hline Estica & 6 & $\checkmark$ & $\checkmark$ & & $\checkmark$ & $\checkmark$ & $\checkmark$ \\
\hline Flame & 7 & $\checkmark$ & $\checkmark$ & & $\checkmark$ & $\checkmark$ & $\checkmark$ \\
\hline Galahad & 6 & $\checkmark$ & $\checkmark$ & $\checkmark$ & $\checkmark$ & $\checkmark$ & $\checkmark$ \\
\hline Haven & 6 & $\checkmark$ & $\checkmark$ & $\checkmark$ & $\checkmark$ & $\checkmark$ & $\checkmark$ \\
\hline Hereward & 6 & $\checkmark$ & $\checkmark$ & $\checkmark$ & $\checkmark$ & $\checkmark$ & $\checkmark$ \\
\hline Hornet & 4 & $\checkmark$ & & & $\checkmark$ & & \\
\hline Hunter & 7 & $\checkmark$ & $\checkmark$ & $\checkmark$ & $\checkmark$ & $\checkmark$ & $\checkmark$ \\
\hline Hussar & 6 & $\checkmark$ & $\checkmark$ & $\checkmark$ & $\checkmark$ & $\checkmark$ & $\checkmark$ \\
\hline Longbow & 3 & & $\checkmark$ & & & $\checkmark$ & \\
\hline Lynx & 6 & $\checkmark$ & & $\checkmark$ & $\checkmark$ & & \\
\hline Mercia & 5 & $\checkmark$ & $\checkmark$ & $\checkmark$ & $\checkmark$ & $\checkmark$ & $\checkmark$ \\
\hline Norman & 4 & $\checkmark$ & $\checkmark$ & $\checkmark$ & $\checkmark$ & $\checkmark$ & $\checkmark$ \\
\hline Pastiche & 7 & & $\checkmark$ & & & $\checkmark$ & $\checkmark$ \\
\hline Rialto & 6 & $\checkmark$ & $\checkmark$ & $\checkmark$ & $\checkmark$ & $\checkmark$ & $\checkmark$ \\
\hline Riband & 3 & $\checkmark$ & $\checkmark$ & $\checkmark$ & $\checkmark$ & $\checkmark$ & $\checkmark$ \\
\hline Ritmo & 5 & & & $\checkmark$ & & & \\
\hline Soissons & 6 & & & $\checkmark$ & & & \\
\hline Spark & 7 & & & $\checkmark$ & & & \\
\hline Zodiac & 6 & $\checkmark$ & $\checkmark$ & & $\checkmark$ & $\checkmark$ & \\
\hline
\end{tabular}

${ }^{a}$ Resistance refers to the rating given for quantitative resistance to septoria leaf blotch; the ratings are limited by the range 1 (susceptible) to 9 (immune) (Anon, 2000). 
Table 2 Full-fungicide programme applied to control all disease

\begin{tabular}{|c|c|c|c|}
\hline Active ingredient(s) & $\begin{array}{l}\text { Commercial product } \\
\text { (c.p.) }\end{array}$ & $\begin{array}{l}\text { Rate } \\
\left(\text { L c.p. ha }{ }^{-1}\right)\end{array}$ & $\begin{array}{l}\text { GS } \\
\text { applied }\end{array}$ \\
\hline Tebuconazole $250 \mathrm{~g} \mathrm{~L}^{-1}+$ triadimenol $125 \mathrm{~g} \mathrm{~L}^{-1}$ & Silvacur ${ }^{\mathrm{a}}$, Bayer ${ }^{\mathrm{b}}$ & $1 \cdot 0$ & 32 \\
\hline \multirow[t]{3}{*}{ Fenpropidin $750 \mathrm{~g} \mathrm{~L}^{-1}$} & Patrol, Syngenta & 0.75 & \\
\hline & Silvacur & $1 \cdot 0$ & 39 \\
\hline & Patrol & 0.75 & \\
\hline Chlorothalonil $375 \mathrm{~g} \mathrm{~L}^{-1}+$ cyproconazole $40 \mathrm{~g} \mathrm{~L}^{-1}$ & Alto Elite, Syngenta & $2 \cdot 0$ & 59 \\
\hline Fenpropimorph $750 \mathrm{~g} \mathrm{~L}^{-1}$ & Corbel, BASF ${ }^{\mathrm{C}}$ & 0.5 & \\
\hline
\end{tabular}

aSyngenta Crop Protection UK Ltd, Whittlesford, Cambridge CB2 4QT, UK.

${ }^{b}$ Bayer CropScience Ltd, Hauxton, Cambridge CB2 5HU, UK.

'BASF plc, Agricultural Division, PO Box 4, Earl Road, Cheadle Hulme SK8 6QG, UK.

Table 3 Treatment thresholds defined to exclude diseases except Mycosphaerella graminicola in untreated plots

\begin{tabular}{llll}
\hline Timing & Powdery mildew & Brown rust & Yellow rust \\
\hline GS31-37 & $1 \%$ on either of & $1 \%$ on any of & $0.5 \%$ on any of \\
& top two leaves & top three leaves & top three leaves \\
GS39-57 & $1 \%$ on any of & $0 \cdot 2 \%$ on any of & $0.5 \%$ on any of \\
& top three leaves & top three leaves & top three leaves \\
GS59-69 & $5 \%$ on either of & $1 \%$ on any of & $1 \%$ on either of \\
& top two leaves & top three leaves & top two leaves \\
\hline
\end{tabular}

untreated plots were suppressed using anilazine [commercial product (c.p.) Dyrene; Bayer, Bury St Edmunds, Suffolk, UK] applied at 2.0 L c.p. ha ${ }^{-1}$ at GS32 and GS39, in order to delay onset of the epidemic on the upper leaves. Varieties were grown in subplots that were a minimum of $2 \times 18 \mathrm{~m}$. Weeds and insect pests were controlled with pesticides, in accordance with normal farm practice.

\section{Disease assessments}

At approximately 10-day intervals from growth stage 31 (GS31, Zadoks et al., 1974), symptom severity (Chiarappa, 1981) and percentage green leaf area were assessed on 10 randomly sampled shoots per plot, on all leaf layers with an average of $25 \%$ or more green leaf area. Symptoms of septoria leaf blotch were estimated as the area covered by pycnidia and all associated senescence. At each assessment date, the absolute areas of the assessed leaves were measured for a subsample of two shoots per plot by the method of Bryson et al. (1997). These measurements, combined with fertile-shoot counts, allowed green area and symptom area to be expressed as dimensionless index values (the planar area of green or symptom area, expressed per unit of ground area that they occupied).

\section{Data analysis}

Areas under both the symptom area index progress curve (AUSAI) and green area index curve [healthy area duration (HAD), sensu Waggoner \& Berger, 1987] were calculated, by the trapezoidal method, across the top three leaves:

$$
\text { area }=\sum_{i}^{n-1} \frac{1}{2}\left[\left(S_{i}+S_{i+1}\right)\left(t_{i+1}-t_{i}\right)\right]
$$

where $S_{i}$ is the symptom or green area index at date $i, t_{i}$ is the number of days between observations, and $n$ is the number of observations.

An extended regression analysis was used to detect differences between varieties in the slope of the fitted straight lines between yield $\left(\mathrm{t} \mathrm{ha}^{-1}\right)$ and both AUSAI and HAD. Maximum information was retained for analysis by pooling datasets across sites. Mixed linear models were fitted using a residual maximum likelihood (REML) method (Patterson \& Thompson, 1971). All analyses were done using Genstat for Windows, fifth edition (Genstat 5 Committee, 1997).

Crop lodging occurred in three experiments: RM96, RM97 (slight) and SX97. Percentage crop lodging was examined as an explanatory variable for yield. This analysis showed a significant effect of lodging for SX97, even after taking variety effects into account, so lodging (\%) was used as an additional explanatory variable in all further analyses of SX97, but was omitted for other experiments.

All models fitted had the same basic form, as a regression of yield on AUSAI or HAD, with both the intercept and slope of the regression allowed to change according to the experiment (all site/season combinations) and the variety:

$$
y_{i j k}=\underbrace{\left(c+v_{i}+e_{j}+e v_{i j}\right)}_{(\mathrm{i})}+\underbrace{\left(\alpha l_{i j k}\right)}_{(\text {ii) }}+\underbrace{\left[\left(\beta+\gamma_{i}+\delta_{j}\right) x_{i j k}\right]}_{(\mathrm{iii})}+\underbrace{\left(b_{j k}+\varepsilon_{i j k}\right)}_{(\mathrm{iv})}
$$

where $y_{i j k}$ is the yield of variety $i$, in experiment $j$, in replicate $k ; l_{i j k}$ is lodging (\%) for variety $i$, in experiment $j$, in replicate $k$; and $x_{i j k}$ is the value of AUSAI (or substitute HAD throughout) for variety $i$, in experiment $j$, in replicate $k$. For the intercept (i), $c$ is a constant term (overall intercept); $v_{i}$ adjusts the intercept for variety $i ; e_{j}$ adjusts 
the intercept for experiment $j$; and $e v_{i j}$ adjusts the intercept for the experiment/variety combination (i.e. allows interaction). The coefficient for the regression on lodging (ii) is $\alpha$. The regression on AUSAI (iii) is represented by $\beta$, the overall slope for the regression of yield on AUSAI; $\gamma$ is an adjustment to the slope for variety $i$; and $\delta_{j}$ is an adjustment to the slope for experiment $j$. The remaining terms (iv) are block error $\left(b_{i k}\right)$ and random error for individual plots $\left(\varepsilon_{i j k}\right)$. Thus, the expected yield for variety $i$ at experiment $j$ with lodging $l$ and AUSAI $\times$ is given by:

$$
\begin{aligned}
& E(\text { yield I variety } i \text {, experiment } j)= \\
& c+v_{i}+e_{j}+\mathrm{ev}_{i j}+\alpha l+\left(\beta+\gamma_{i}+\delta_{j}\right) x
\end{aligned}
$$

where random effects were fitted for experiment, variety/ experiment interaction and errors with variances, so that:

$$
\begin{aligned}
& E\left(e_{j}\right)=E\left(\mathrm{ev}_{i j}\right)=E\left(\delta_{j}\right)=E\left(b_{i k}\right)=E\left(\varepsilon_{i j k}\right)=0 \\
& \operatorname{Var}\left(\begin{array}{l}
e_{j} \\
\delta_{i}
\end{array}\right)=\left(\begin{array}{ll}
\sigma_{e}^{2} \\
\sigma_{e \delta} & \sigma_{\delta}^{2}
\end{array}\right) ; \operatorname{cov}\left(e_{j}, \delta_{k}\right)=0 \text { for } j \neq k \\
& \operatorname{Var}\left(e v_{i j}\right)=\sigma_{e v}^{2} ; \operatorname{Var}\left(b_{j k}\right)=\sigma_{b j}^{2} ; \operatorname{Var}\left(\varepsilon_{i j k}\right)=\sigma_{j}^{2}
\end{aligned}
$$

All random effects were assumed to be normally distributed and, except where shown, were assumed to be independent.

To account for differences in variability between experiments, the basic model included a variance component for blocks, where necessary, and a separate error variance for each experiment. This had the effect of reducing the weight of data points from more variable experiments. To account for differences in the overall relationship caused by intrinsic site/year (i.e. experiment) differences, adjustments to the intercept and slope were allowed for an experiment effect. Adjustments to the intercept were also allowed for each variety/experiment combination. Thus, the experiments were regarded as a set of random environments over which variety effects were assessed. Two forms of the basic model were compared. The first was a fixed-effects model, where no prior assumptions were made about the form of the variety slopes; the analysis was used to detect evidence of differences in slope between varieties and the estimates of slope were used to compare varieties. The other form was a random-effects model, which assumed that deviations in individual variety slopes away from the mean slope formed a normal random population with some unknown variance. This required the additional conditions:

$$
\begin{aligned}
& E\left(v_{i}\right)=E\left(\gamma_{i}\right)=0 \\
& \operatorname{Var}\left(\begin{array}{l}
v_{i} \\
\gamma_{i}
\end{array}\right)=\left(\begin{array}{ll}
\sigma_{v}^{2} \\
\sigma_{v \gamma} & \sigma_{\gamma}^{2}
\end{array}\right) ; \operatorname{cov}\left(v_{i}, \gamma_{k}\right)=0 \text { for } j \neq k
\end{aligned}
$$

Thus, varieties were regarded as a random population with variation, assessed over a random set of environments. Given a population of varieties with no particular structure, this was considered a reasonable assumption. The analysis was used to assess whether there was evidence of significant variation between variety slopes and produce predictions (best linear unbiased predictions, BLUPs) of variety slopes.
Both forms of model were also fitted for the relationship between yield and HAD.

\section{Results}

Disease pressure was low at Rosemaund in 1995, severe at Rosemaund in 1996 and moderate in the remaining experiments. Large differences between varieties were measured in yield loss in all three years (Table 4$)$. These differences exhibited some correlation with resistance ratings published for septoria leaf blotch in the UK recommended list (Fig. 1). However, considerable overlap was evident in the ranges of yield loss for the five resistance ratings represented in the dataset, and three varieties, Avalon, Hornet and Soissons, conformed poorly to the relationship. A preliminary comparison showed that little disease developed on varieties Ritmo, Soissons, Spark and Hornet. Therefore, the range in AUSAI and HAD for these varieties was small and they were excluded from further analyses that used the fixed-effects model.

\section{Relationship between AUSAI and yield}

Attainable yield, measured as yield with the full spray programme, varied substantially by variety, site and season. Plots of yield against AUSAI showed a linear relationship within experiments, but large differences in slope were evident between experiments (Fig. 2).

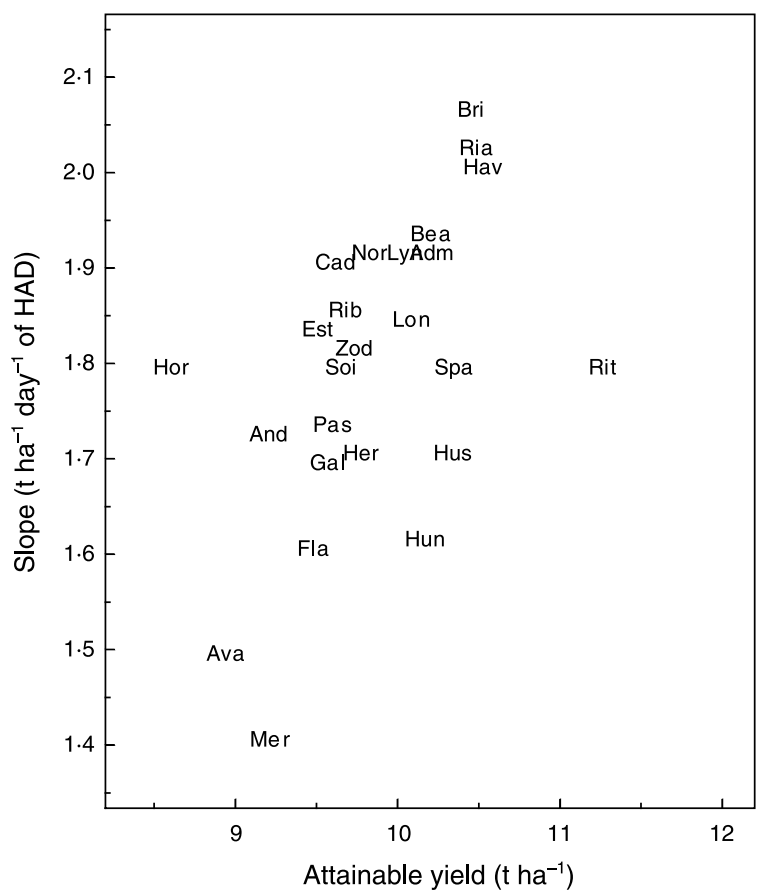

Figure 1 Correlation between Mycosphaerella graminicola resistance rating and yield. Variety means are calculated across field experiments at Rosemaund and Starcross over three seasons during 1995-97. 
Table 4 Difference in yield between full fungicide and untreated plots at Rosemaund (RM) and Starcross (SX) in three seasons, 1995-97

\begin{tabular}{|c|c|c|c|c|c|c|}
\hline \multirow[b]{2}{*}{ Variety } & \multicolumn{6}{|c|}{ Yield loss $\left(\mathrm{t} \mathrm{ha}^{-1}\right)$} \\
\hline & SX95 & SX96 & SX97 & RM95 & RM96 & RM97 \\
\hline Admiral & 0.58 & 0.33 & $2 \cdot 74$ & $1 \cdot 10$ & $1 \cdot 35$ & 3.90 \\
\hline Andante & 0.01 & 1.04 & $1 \cdot 50$ & 0.67 & $1 \cdot 56$ & $2 \cdot 25$ \\
\hline Avalon & $-0 \cdot 36$ & $1 \cdot 25$ & $0 \cdot 31$ & 0.35 & $1 \cdot 20$ & $2 \cdot 74$ \\
\hline Beaver & 0.31 & 0.87 & $1 \cdot 85$ & $0 \cdot 64$ & $1 \cdot 15$ & $3 \cdot 69$ \\
\hline Brigadier & $0 \cdot 74$ & $1 \cdot 65$ & 3.87 & 0.91 & $2 \cdot 11$ & $4 \cdot 50$ \\
\hline Cadenza & -0.04 & $1 \cdot 29$ & $1 \cdot 98$ & 0.58 & $2 \cdot 75$ & 3.99 \\
\hline Estica & 0.95 & $1 \cdot 13$ & - & 0.25 & $1 \cdot 35$ & 3.09 \\
\hline Flame & 0.33 & 0.63 & - & 0.52 & $1 \cdot 00$ & $2 \cdot 45$ \\
\hline Galahad & -0.06 & $1 \cdot 45$ & $1 \cdot 68$ & 0.24 & $1 \cdot 34$ & $3 \cdot 34$ \\
\hline Haven & $0 \cdot 10$ & 0.68 & $2 \cdot 21$ & 0.93 & $1 \cdot 74$ & 4.03 \\
\hline Hereward & 0.59 & 1.04 & 1.90 & $0 \cdot 61$ & $1 \cdot 64$ & $2 \cdot 52$ \\
\hline Hornet & -0.23 & - & - & 0.43 & - & - \\
\hline Hunter & 0.06 & $1 \cdot 87$ & $1 \cdot 38$ & $0 \cdot 68$ & $1 \cdot 63$ & $3 \cdot 76$ \\
\hline Hussar & 0.67 & $1 \cdot 87$ & $2 \cdot 80$ & 0.89 & 1.54 & $4 \cdot 03$ \\
\hline Longbow & - & $1 \cdot 66$ & - & - & $2 \cdot 66$ & - \\
\hline Lynx & $-0 \cdot 15$ & - & $1 \cdot 86$ & $0 \cdot 28$ & - & - \\
\hline Mercia & 0.69 & $1 \cdot 58$ & $2 \cdot 21$ & $1 \cdot 08$ & $2 \cdot 49$ & $2 \cdot 82$ \\
\hline Norman & $0 \cdot 46$ & $2 \cdot 06$ & 1.94 & 0.91 & $2 \cdot 07$ & $4 \cdot 01$ \\
\hline Pastiche & - & $1 \cdot 07$ & - & - & $1 \cdot 10$ & $1 \cdot 14$ \\
\hline Rialto & $0 \cdot 24$ & $1 \cdot 39$ & 1.53 & 0.58 & $1 \cdot 61$ & $2 \cdot 96$ \\
\hline Riband & $1 \cdot 12$ & 1.97 & $4 \cdot 36$ & $1 \cdot 11$ & $2 \cdot 66$ & $3 \cdot 74$ \\
\hline Ritmo & - & - & $2 \cdot 24$ & - & - & - \\
\hline Soissons & - & - & $0 \cdot 31$ & - & - & - \\
\hline Spark & - & - & $1 \cdot 20$ & - & - & - \\
\hline Zodiac & 0.45 & $1 \cdot 40$ & - & 1.25 & 1.59 & - \\
\hline
\end{tabular}

\section{Fixed-effects model}

The relationship between yield and AUSAI fitted poorly unless adjustment was made for sites. This adjustment dominated the analysis and there was no evidence of any difference in AUSAI slopes between varieties (Wald statistic 15.86 on 20 d.f., $P=0.725$ ). The correlation coefficent $r$ between yield and fitted values from the AUSAI model was $0 \cdot 878$. Because of the lack of any significant variety effect in this analysis, the random-effects model was not fitted.

\section{Relationship between HAD and yield}

Plots of yield against HAD showed an approximately linear relationship. Variation about the linear relationship differed between sites (Fig. 3).

\section{Fixed-effects model}

Some evidence was found (Wald statistic 30.2 on 20 d.f., $P=0.067)$ of differences in slopes between varieties. Variety slopes with their SEs are shown in Table 5 . The correlation coefficient of the fitted values with the data was $r=0 \cdot 879$. The fitted values included all terms except block and random error.

An overall LSD value could not be specified because the degrees of freedom were not easily defined and the SED differed for each pair of variety effects. However, a
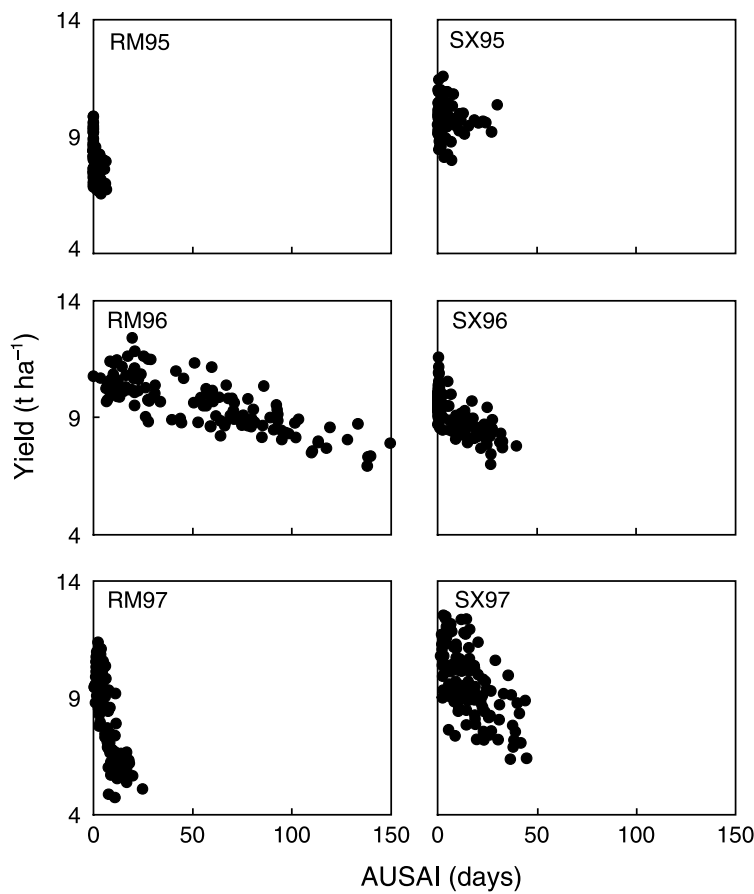

Figure 2 Yield against area under the symptom area index progress curve (AUSAI) at Rosemaund and Starcross in three seasons during 1995-97. 
Table 5 Estimates of slope for the relationship between healthy area duration (HAD) and yield. Slopes were fitted by random- and fixed-effects analyses (see text for details). Varieties are ordered with reference to slope of the random-effects model. According to that model, varieties above the upper dividing line were tolerant, while those below the lower dividing line were intolerant

\begin{tabular}{|c|c|c|c|c|c|c|c|}
\hline \multirow[b]{2}{*}{ Variety } & \multicolumn{3}{|c|}{ Random-effects analysis } & \multicolumn{2}{|c|}{ Fixed-effects analysis } & \multirow[b]{2}{*}{$\begin{array}{l}\text { Observations } \\
\text { in analysis } \\
\text { (all data) }\end{array}$} & \multirow[b]{2}{*}{$\begin{array}{l}\text { Percentage } \\
\text { range of HAD } \\
(100 \%=354)\end{array}$} \\
\hline & $\begin{array}{l}\text { Slope prediction } \\
\left(\mathrm{t} \mathrm{ha} \mathrm{a}^{-1} \mathrm{day}^{-1}\right. \\
\text { of HAD) }\end{array}$ & $\begin{array}{l}\text { Variety } \\
\text { slope } \\
\text { BLUP }\end{array}$ & $\begin{array}{l}\text { Prediction } \\
\text { standard } \\
\text { error }^{\mathrm{a}}\end{array}$ & $\begin{array}{l}\text { Slope estimate } \\
\left(\mathrm{t} \mathrm{ha} \mathrm{d}^{-1} \text { day }^{-1}\right. \\
\text { of HAD) }\end{array}$ & SE of slope & & \\
\hline Mercia & $1 \cdot 41 \mathrm{E}-02$ & $-0 \cdot 39 \mathrm{E}-02$ & 0.08E-02 & 1.53E-02 & $0 \cdot 31 \mathrm{E}-02$ & 36 & $84 \cdot 7$ \\
\hline Avalon & $1 \cdot 50 \mathrm{E}-02$ & $-0 \cdot 30 \mathrm{E}-02$ & 0.08E-02 & 1.46E-02 & $0 \cdot 34 \mathrm{E}-02$ & 36 & $77 \cdot 2$ \\
\hline Flame & $1 \cdot 61 \mathrm{E}-02$ & $-0 \cdot 19 \mathrm{E}-02$ & $0.08 \mathrm{E}-02$ & $1 \cdot 41 \mathrm{E}-02$ & 0.33E-02 & 30 & $75 \cdot 7$ \\
\hline Hunter & 1.62E-02 & $-0 \cdot 18 \mathrm{E}-02$ & 0.07E-02 & 1.57E-02 & $0.31 \mathrm{E}-02$ & 36 & $86 \cdot 0$ \\
\hline Galahad & $1 \cdot 70 \mathrm{E}-02$ & $-0 \cdot 10 \mathrm{E}-02$ & $0.08 \mathrm{E}-02$ & $1 \cdot 72 \mathrm{E}-02$ & $0.34 \mathrm{E}-02$ & 35 & $68 \cdot 0$ \\
\hline Hussar & $1 \cdot 71 \mathrm{E}-02$ & $-0 \cdot 10 \mathrm{E}-02$ & 0.07E-02 & 1.64E-02 & $0 \cdot 31 \mathrm{E}-02$ & 36 & $82 \cdot 7$ \\
\hline Hereward & $1 \cdot 71 \mathrm{E}-02$ & -0.09E-02 & 0.08E-02 & 1.76E-02 & $0 \cdot 35 \mathrm{E}-02$ & 36 & $88 \cdot 0$ \\
\hline Andante & $1 \cdot 73 \mathrm{E}-02$ & $-0.07 \mathrm{E}-02$ & 0.09E-02 & $1 \cdot 85 \mathrm{E}-02$ & $0.35 \mathrm{E}-02$ & 36 & $68 \cdot 8$ \\
\hline Pastiche & $1 \cdot 74 \mathrm{E}-02$ & $-0.06 \mathrm{E}-02$ & $0 \cdot 10 \mathrm{E}-02$ & $1.50 \mathrm{E}-02$ & $0.48 \mathrm{E}-02$ & 18 & $44 \cdot 3$ \\
\hline Soissons & 1.80E-02 & 0.00E-02 & 0.19E-02 & - & - & $0(6)$ & $19 \cdot 3$ \\
\hline Spark & $1 \cdot 80 \mathrm{E}-02$ & $0.00 \mathrm{E}-02$ & $0.19 \mathrm{E}-02$ & - & - & $0(6)$ & $18 \cdot 8$ \\
\hline Ritmo & $1 \cdot 80 \mathrm{E}-02$ & $0.00 \mathrm{E}-02$ & $0 \cdot 19 \mathrm{E}-02$ & - & - & $0(6)$ & $17 \cdot 9$ \\
\hline Hornet & $1 \cdot 80 \mathrm{E}-02$ & 0.00E-02 & 0.19E-02 & - & - & $0(12)$ & $31 \cdot 7$ \\
\hline Zodiac & $1 \cdot 82 \mathrm{E}-02$ & $0.02 \mathrm{E}-02$ & 0.09E-02 & 1.74E-02 & $0.36 \mathrm{E}-02$ & 24 & $83 \cdot 2$ \\
\hline Estica & 1.84E-02 & 0.03E-02 & 0.09E-02 & $2 \cdot 15 \mathrm{E}-02$ & $0 \cdot 36 \mathrm{E}-02$ & 30 & $60 \cdot 5$ \\
\hline Longbow & $1 \cdot 85 \mathrm{E}-02$ & 0.05E-02 & $0 \cdot 11 E-02$ & $2 \cdot 24 \mathrm{E}-02$ & $0 \cdot 42 \mathrm{E}-02$ & 12 & $49 \cdot 1$ \\
\hline Riband & 1.86E-02 & 0.06E-02 & 0.09E-02 & $2 \cdot 25 \mathrm{E}-02$ & 0.33E-02 & 36 & $61 \cdot 9$ \\
\hline Cadenza & $1.91 \mathrm{E}-02$ & $0.11 \mathrm{E}-02$ & 0.09E-02 & $1.94 \mathrm{E}-02$ & $0.33 \mathrm{E}-02$ & 36 & $91 \cdot 2$ \\
\hline Admiral & 1.92E-02 & $0 \cdot 12 \mathrm{E}-02$ & 0.08E-02 & 1.97E-02 & 0.34E-02 & $35(36)$ & $73 \cdot 3$ \\
\hline Lynx & 1.92E-02 & $0 \cdot 12 \mathrm{E}-02$ & $0 \cdot 10 \mathrm{E}-02$ & 1.84E-02 & $0 \cdot 38 \mathrm{E}-02$ & 18 & $77 \cdot 8$ \\
\hline Norman & 1.92E-02 & $0.12 \mathrm{E}-02$ & $0.08 \mathrm{E}-02$ & $2 \cdot 20 \mathrm{E}-02$ & $0.34 \mathrm{E}-02$ & 36 & $74 \cdot 3$ \\
\hline Beaver & 1.94E-02 & $0 \cdot 13 \mathrm{E}-02$ & 0.08E-02 & 1.89E-02 & 0.33E-02 & 36 & $89 \cdot 4$ \\
\hline Haven & 2.01E-02 & 0.21E-02 & 0.08E-02 & 1.90E-02 & $0 \cdot 34 \mathrm{E}-02$ & 36 & $77 \cdot 6$ \\
\hline Rialto & 2.03E-02 & $0.23 \mathrm{E}-02$ & $0.08 \mathrm{E}-02$ & $2 \cdot 13 \mathrm{E}-02$ & $0.33 \mathrm{E}-02$ & 36 & $75 \cdot 0$ \\
\hline Brigadier & 2.07E-02 & $0 \cdot 27 \mathrm{E}-02$ & $0.08 \mathrm{E}-02$ & 2.06E-02 & 0.32E-02 & 36 & $74 \cdot 8$ \\
\hline
\end{tabular}

BLUP, best linear unbiased predictions.

aSquare root of the prediction error variance.

reasonable number of degrees of freedom can be assumed, so differences greater than $2 \times$ SED were taken as significant for any pair of varieties. Mercia, Avalon and Flame (but not Pastiche) were significantly more tolerant than Brigadier. Conversely, varieties Brigadier, Rialto, Norman, Riband and Estica were significantly less tolerant than Mercia.

\section{Random-effects model}

A likelihood ratio test showed strong evidence (change in residual likelihood of 16.2 on 2 d.f., $P<0.001$ ) of significant variation between variety slopes. The correlation coefficient of the fitted values with the data was $r=0 \cdot 872$. Again, the fitted values included all terms except block and random error.

The estimated slope for each variety, the deviation away from the mean slope (BLUP) and the prediction error variance for the BLUPs are given in Table 5. Positive BLUP values indicate larger than average slopes and imply intolerant varieties, because disease-induced loss of green leaf area has a large effect on yield. In contrast, negative values indicate lower than average slopes and imply tolerant varieties. When the variety slope BLUPs were compared with their prediction standard errors, varieties Brigadier, Haven and Rialto showed evidence of intolerance, whilst
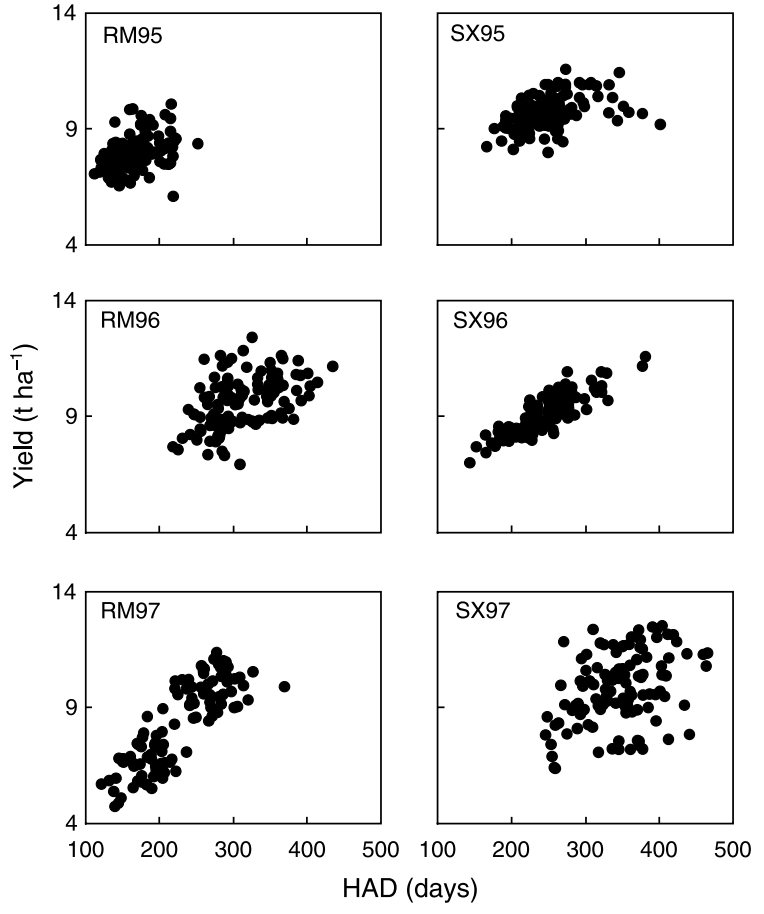

Figure 3 Yield against healthy area duration (HAD) at Rosemaund and Starcross in three seasons during 1995-97. 


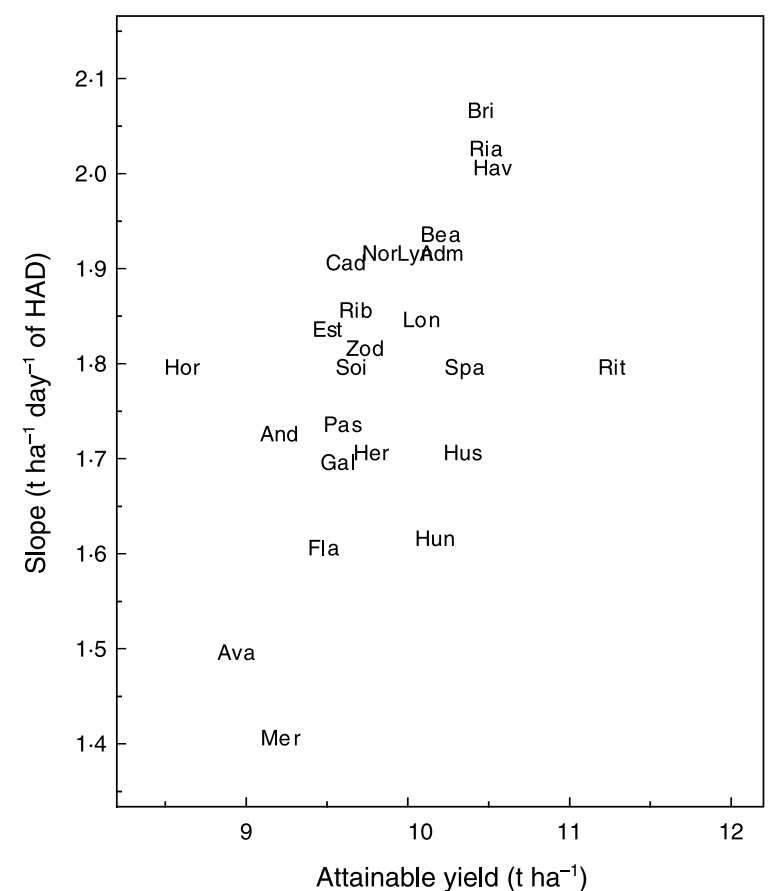

Figure 4 Plot of variety slopes estimated by the random-effects model against attainable yield (expressed as the mean fungicide-treated yield).

varieties Avalon, Mercia, Flame and Hunter showed evidence of tolerance (Table 5).

A plot of the estimated slope for each variety against yield potential (expressed as the mean treated yield) indicated that tolerance was associated weakly with low attainable yield (Fig. 4).

\section{Comparison of the random and fixed models}

The varieties in Table 5 are ordered by the BLUP estimate of slope. A difference in ordering is evident between the fixed- and random-effects analyses. Both identified Avalon, Mercia and Flame as tolerant and Brigadier and Rialto as intolerant. However, there was disagreement about Haven, Hunter, Riband and Estica.

\section{Differences in slopes within varieties between experiments}

A test was made to check for consistency in slopes between experiments (after taking overall site/year effects into account). A separate slope was fitted to each variety within each experiment. An accurate estimate of slope could not be obtained where the range in HAD was small. Therefore, for this test within experiments, varieties were retained for investigation only where the range of HAD was greater than that expected from random error. Because the error differed between experiments, the criteria for retaining varieties were different for each experiment (Table 6).
Table 6 Critical range for healthy area duration (HAD) to be greater than random error

\begin{tabular}{lc}
\hline Experiment & Critical range \\
\hline Rosemaund 95 & $96 \cdot 0$ \\
Rosemaund 96 & $92 \cdot 5$ \\
Rosemaund 97 & $91 \cdot 3$ \\
Starcross 95 & $127 \cdot 8$ \\
Starcross 96 & $78 \cdot 4$ \\
Starcross 97 & $127 \cdot 4$ \\
\hline
\end{tabular}

Separate intercepts were allowed for all combinations of experiment and variety, and for overall slopes against HAD for each variety and for each experiment, and then separate slopes for each variety at each experiment. Separate error variances were used for each experiment.

For HAD, the Wald tests for separate slopes within varieties between experiments indicated that separate slopes were not required $(P=0 \cdot 51)$. This evidence for consistent slopes, within varieties between experiments, indicated that it was appropriate to use estimates of consistent differences between varieties using the whole dataset.

\section{Predicting yield loss: comparison of HAD and AUSAI models}

To predict yield loss at any site, given just the expected value of HAD or AUSAI, models independent of specific site information were necessary. The fits of the models for AUSAI and HAD were similar when experiment effects were taken into account. These models were refitted without taking account of experiment effects, other than random error. These forms of the model were not suitable for comparing varietal slopes, because different varieties occurred in each experiment and some experiment effects were therefore fitted as part of the variety effects because of confounding. Consequently, in this analysis, some variety differences contained contributions from site differences. The model for AUSAI gave a poor fit to the data $(r=0 \cdot 21)$. The fit for HAD was similar for the fixed and random models $(r=0.767$ and 0.760 , respectively).

\section{Discussion}

Evidence of differences in tolerance, measured as response of yield to disease-induced changes in HAD, was found across a comparison of 21 commercial varieties. These differences were large enough to be of agronomic importance. For example, in Mercia the sensitivity of yield to green area loss was approximately $30 \%$ lower than in Brigadier. On a limited subset of the data, there was no evidence that tolerance, quantified through measurement of HAD, differed within varieties between experiments. This indicates that genotypic differences were responsible for the differences in tolerance. Tolerance was not detectable through measurements of disease quantified as symptom area index. Variation in disease and yield were provided by measurements taken across fungicide treatments, sites 


\begin{tabular}{|c|c|c|c|c|c|}
\hline Variety & Rht & 1BL/1RS & $\begin{array}{l}\text { Photoperiod } \\
\text { sensitivity }\end{array}$ & Cultivated & Year of release \\
\hline Mercia & No & No & S & UK & 86 \\
\hline Avalon & 2 & No & S & UK & 80 \\
\hline Flame & 2 & No & S & UK & 94 \\
\hline Hunter & 2 & Yes & S & UK & 93 \\
\hline Galahad & 2 & No & S & UK & 83 \\
\hline Hussar & 2 & Yes & $\mathrm{S}$ & UK & 92 \\
\hline Hereward & 2 & No & $\mathrm{S}$ & UK & 91 \\
\hline Andante & 2 & & $\mathrm{~S}$ & UK & \\
\hline Pastiche & 2 & No & S & UK & 89 \\
\hline Soissons & 1 & No & I & France & 95 \\
\hline Spark & No & No & S & UK & 93 \\
\hline Ritmo & 2 & No & S & Netherlands & \\
\hline Hornet & 2 & Yes & $\mathrm{S}$ & UK & 87 \\
\hline Zodiac & & & S & UK & \\
\hline Estica & & No & S & Netherlands & \\
\hline Longbow & 2 & No & $\mathrm{S}$ & UK & 83 \\
\hline Riband & 2 & No & S & UK & 89 \\
\hline Cadenza & No & No & S & UK & 94 \\
\hline Admiral & 2 & Yes & S & UK & 92 \\
\hline Lynx & 2 & Yes & $\mathrm{S}$ & UK & 91 \\
\hline Norman & 2 & No & $\mathrm{S}$ & UK & 81 \\
\hline Beaver & 2 & Yes & $\mathrm{S}$ & UK & 90 \\
\hline Haven & 2 & Yes & $\mathrm{S}$ & UK & 90 \\
\hline Rialto & 2 & Yes & $\mathrm{S}$ & UK & 95 \\
\hline Brigadier & 2 & Yes & S & UK & 93 \\
\hline
\end{tabular}

Table 7 Varieties categorized for reduced height (Rht) genes, 1BL/RS rye chromosome translocation, photoperiod insensitivity, country of cultivation and year first included on the UK recommended list. According to the randomeffects model, varieties above the upper dividing line were tolerant, while those below the lower dividing line were intolerant to septoria leaf blotch and seasons. However, symptom measurements do not provide accurate quantification of the impact of green canopy area loss on light capture. The importance of such quantification in defining consistent disease-yield-loss equations is now well established (Madden \& Nutter, 1995; Bryson et al., 1997).

Visual estimates of disease severity and green leaf area are prone to serious error (Forbes \& Jeger, 1987; Parker et al., 1995). Typically, low disease severity is grossly overestimated and disease above $25-50 \%$ is underestimated. The use of such disease estimates inevitably compromise attempts to quantify disease tolerance. Overestimation of small amounts of disease result in overestimation of tolerance, because the loss of yield per unit of disease is underestimated. This suggests that resistant varieties might be wrongly attributed as tolerant. Similarly, underestimation of high disease severity could lead to underestimation of tolerance in susceptible varieties. Such errors will be most evident where individual observations of disease for a group of varieties are plotted against yield loss and differences in tolerance are detected by deviations from the fitted line, e.g. as used in the work of Newton et al. (1998). To some extent, the problem is ameliorated where separate slopes are fitted for each variety, because disease estimates given by observers generally conform to a linear function related to the true disease severity (Parker et al., 1995). In this study varieties displaying evidence of tolerance and intolerance were identified across the range of resistance present in commercial varieties. However, considering the limitations of visual estimates of disease and green area, it is possible that the magnitude of the range between tolerance and intolerance is underestimated.

Differences in ordering of the varieties for tolerance were found between random- and fixed-effects analyses. Both analyses identified Mercia, Avalon and Flame as tolerant, and Brigadier and Rialto as intolerant. However, Riband and Estica, identified as intolerant by the fixedeffects analysis, were not distinguished as such by the random-effects model. Similarly, Haven and Hunter, shown to be tolerant and intolerant, respectively, by the randomeffects model, were indistinguishable from the average varietal tolerance by the fixed-effects analysis. In simple cases, BLUP estimates can be obtained from fixed-effect estimates by applying a shrinkage factor proportional to the amount of information available. Shrinkage is towards the population mean. In the dataset reported here, shrinkage occurred for three reasons: (i) the number of observations available (small number gave larger shrinkage); (ii) the range of HAD values available for the variety (small range, or values concentrated at the centre of the range, caused larger shrinkage); and (iii) the degree of error present in the experiments where a variety was present (presence only in experiments with larger errors caused larger shrinkage). This shrinkage accounts for the different test results for variety slopes given by the random- and fixed-effects analyses. In the random-effects model, slopes for Riband and Estica were penalized towards the population mean because of a small range of HAD values. Estica was further penalized, in the same direction, for not appearing in all experiments. In contrast, Haven and Hunter both had larger ranges, appeared at all sites and 
had evenly distributed values. The prediction-error variances for the random model (random equivalent of SES) were smaller than the fixed-effect SEs because fewer assumptions about the form of the effects were made in the random model.

The slope for the relationship between disease and yield has been used by previous authors to quantify tolerance (Ziv \& Eyal, 1976; Newton et al., 1998). In both cases, yield differences were expressed in proportional terms, i.e. as a percentage of the healthy (fungicide-treated) yield. This expression of yield loss is difficult to reconcile with the objective of detecting tolerance. Crop yield is dependent on resource capture, which is most appropriately quantified on absolute scales (Paveley et al., 2001). Differences between varieties in the efficiencies of resource capture when diseased are exhibited as tolerance, which is tested using the null hypothesis that all varieties are identical. Consider the comparison, in a given environment, of two varieties with different attainable yields: variety A with $10 \mathrm{tha}^{-1}$ and variety $\mathrm{B}$ with $8 \mathrm{tha}^{-1}$. If both suffer identical levels of disease and proportionally identical losses of $50 \%$ yield, the loss in variety $\mathrm{A}$ is $5 \mathrm{t} \mathrm{ha}^{-1}$ and that in $\mathrm{B}$ is $4 \mathrm{t} \mathrm{ha}^{-1}$. Thus, if tolerance is defined as the slope for the relationship between disease and relative yield, there is no difference between varieties A and B. However, a type II error occurs because the null hypothesis is accepted, when in fact variety $B$ is more tolerant.

Gaunt (1981) suggested that, to demonstrate a variety as tolerant, the yield potential should be equivalent to nontolerant varieties. This requirement could more appropriately be stated as a breeding objective. Tolerance present within modern lines does not occur as a result of specific selection of associated traits. From the 1980s to the mid1990s, European wheat prices and the relatively low costs of fungicides reduced the commercial incentive to breed varieties with good disease escape, resistance and tolerance. In addition, the UK variety trials system, which has placed great emphasis on treated yield, has acted to focus plant breeders on the achievement of greater attainable yield. It is likely that some traits conferring tolerance have associated yield penalties. Equally, however, some may have positive or neutral effects on attainable yield. In this study there was evidence for tolerance being associated with lower yield potential. However, the most tolerant varieties were also the older varieties. Given the large increase in yield achieved through breeding in the past two decades, it is possible that the correlation of tolerance with low yield is spurious. Instead, breeding efforts might have inadvertently selected out tolerance traits that are compatible with high yield.

In the spring wheat variety Miriam, the rate of carbon fixation per unit of chlorophyll was greater in diseased than in healthy plants (Zuckerman et al., 1997). Measurements of carbon fixation were made in the laboratory. This parameter is difficult to measure for comparison of large numbers of varieties in the field; demonstration under field conditions was a key requirement of Gaunt's (1981) tests for tolerance. A previous field study, using sequential measurements of crop growth and light interception to estimate radiation use efficiency (RUE), showed high RUE for the varieties identified as intolerant here (Haven, Rialto and Brigadier). In contrast, the tolerant varieties Mercia and Avalon were shown to have lower RUE (Foulkes et al., 1998). Empirical evidence suggests that this difference in RUE may be associated with the 1BL/ 1RS chromosome translocation (Foulkes et al., 1998). Indeed, Flame, which was found to be tolerant in this study, does not contain 1BL/1RS (Table 7). An association of intolerance with high RUE is plausible, since each unit area of green lamina lost to disease would have been more productive than in a low-RUE variety. More speculatively, varieties operating close to optimum photosynthetic efficiency may be unable to compensate for losses in green area by increasing the photosynthetic efficiency of that which remains.

It is difficult to determine which of the agronomically important traits introduced by plant breeding over the past two decades have reduced tolerance. Nevertheless, the evidence presented here can be used in conjunction with arguments from first principles to set up testable hypotheses for the causes of disease tolerance. Thus, candidate traits to impart disease tolerance are:

- canopy size - larger canopy size conferring tolerance through increased ability to maintain radiation interception during grain filling, per unit green area loss to disease;

- extinction coefficient - higher extinction coefficient conferring tolerance through greater interception of radiation per unit remaining green area;

- stem reserve capacity - larger reserves conferring tolerance to late-season diseases through increased ability to compensate for lost radiation interception during grain filling by buffering from carbohydrate stores laid down in stems pre-GS 71;

- leaf photosynthetic rate - once infected, tolerant varieties maintain or enhance photosynthetic capacity of the remaining healthy green area.

The potential for further progress in understanding and quantifying tolerance using commercial varieties is limited, because they differ widely across their genomes, as well as in the genes controlling putative tolerance traits. Corroboration of the association between traits and tolerance could be achieved by studying isogenic lines that vary only for the major genes believed to associate with the tolerance traits, or doubled haploid mapping populations from crosses between parents with high and low trait expression.

The current analysis of UK National and Recommended List variety trials uses fixed variety effects (Patterson \& Silvey, 1980). Therefore, models of the key variates that quantify performance are optimized to fit the relevant datasets. In contrast, the random-effects model used in this study takes into account the prediction of future values (Cullis et al., 2000). This difference accounts for the slightly greater correlation value of the fixed-effects model. Thus, the difference in $r$ does not imply that the fixedeffects model is more appropriate. Indeed, given that the aim of the comparisons was to predict the expression of 
variety tolerance, the random-effects model has implicit theoretical advantages. The same argument might be applied equally to the analysis of NL/RL trials, particularly since other authors have shown that random-effects models provide an efficient and reliable approach for analysing multisite and multiseason variety evaluation experiments (Cullis et al., 2000).

\section{Acknowledgements}

The Department for Environment, Food and Rural Affairs (DEFRA) funded this work. We are grateful to colleagues in ADAS for collecting the experimental data.

\section{References}

Anonymous, 2000. Cereals Variety Handbook. NIAB UK Recommended Lists of Cereals. Cambridge, UK: National Institute of Agricultural Botany.

Bryson RJ, Paveley ND, Clark ND, Sylvester-Bradley R, Scott RK, 1997. Use of in-field measurements of green leaf area and incident radiation to estimate the effects of yellow rust epidemics on the yield of winter wheat. European Journal of Agronomy 7, 53-62.

Chiarappa L, 1981. Crop Loss Assessment Methods Supplement 3. Wallingford, UK: CAB International.

Cobb NA, 1894. Contributions to an economic knowledge of Australian rusts (Uredineae). Chapter 10. Agricultural Gazette of New South Wales 5, 239-50.

Cullis BR, Smith A, Hunt C, Gilmour A, 2000. An examination of the efficiency of Australian crop variety evaluation programmes. Journal of Agricultural Sciences 135, 213-22.

Forbes GA, Jeger MJ, 1987. Factors affecting the estimation of disease intensity in simulated plant structures. Zeitschrift für Pflanzenkrankheiten und Pflanzenschutz 94, 113-20.

Foulkes MJ, Scott RK, Sylvester-Bradley R, Pickett A, 1998. Variety typing trials and NIAB additional character assessments. Home-Grown Cereals Authority Final Project Report No. 174, Vol. V. London, UK: HGCA.

Gaunt RE, 1981. Disease tolerance - an indicator of thresholds. Phytopathology 71, 915-6.

Genstat 5 Committee, 1997. Genstat 5 Release $4 \cdot 1$ Reference Manual. Oxford, UK: Nag Ltd.

Lovell DJ, Parker SR, Hunter T, Royle DJ, Coker RR, 1997. Influence of crop growth and canopy structure on the risk of epidemics by Mycosphaerella graminicola (Septoria tritici) in winter wheat. Plant Pathology 47, 126-38.

Madden LV, Nutter FW, 1995. Modelling crop losses at the field scale. Canadian Journal of Plant Pathology 17, 124-37.

Newton AC, Thomas WTB, Guy DC, Gaunt RE, 1998. The interaction of fertilizer treatment with tolerance to powdery mildew in spring barley. Field Crops Research 55, 45-56.
Nutter FW, Teng PS, Royer MH, 1993. Terms and concepts for yield, crop loss and disease thresholds. Plant Disease 77, 211-5.

van Oijen M, 1990. Photosynthesis is not impaired in healthy tissue of blighted potato plants. Netherlands Journal of Plant Pathology 96, 55-63.

Parker SR, Shaw MW, Royle DJ, 1995. The reliability of visual estimates of disease severity on cereal leaves. Plant Pathology 44, 856-64.

Patterson HD, Silvey V, 1980. Statutory and recommended list trials of crop varieties in the United Kingdom. Journal of the Royal Statistical Society, Series A 143, 219-52.

Patterson HD, Thompson R, 1971. Recovery of inter-block information when block sizes are unequal. Biometrika 58, 545-54.

Paveley ND, 1999. Integrating Septoria risk variables. In: Lucas JA, Bowyer P, Anderson HM, eds. Septoria on Cereals: a Study of Pathosystems. Wallingford, UK: CABI Publishing, 230-50.

Paveley ND, Lockley D, Sylvester-Bradley R, Thomas J, 1997. Determinants of fungicide spray decisions for wheat. Pesticide Science 49, 379-88.

Paveley ND, Sylvester-Bradley R, Scott RK, Craigon J, Day W, 2001. Steps in predicting the relationship of yield on fungicide dose. Phytopathology 91, 708-16.

Seck M, Roelfs AP, Teng PS, 1991. Influence of leaf position on yield loss caused by wheat leaf rust in single tillers. Crop Protection 10, 222-32.

Shaw MW, Royle DJ, 1989. Estimation and validation of a function describing the rate at which Mycosphaerella graminicola causes yield loss in winter wheat. Annals of Applied Biology 115, 425-42.

Spitters CJT, Roermund HJW, van Nassau HGMG, Schepers J, Mesdag J, 1990. Genetic variation in partial resistance to leaf rust in winter wheat: disease progress, foliage senescence and yield reduction. Netherlands Journal of Plant Pathology 96, 3-15.

Thorne GN, Pearman I, Day W, Todd AD, 1988. Estimation of radiation interception by winter wheat from measurements of leaf area. Journal of Agricultural Science 110, 101-8.

Waggoner PE, Berger RD, 1987. Defoliation, disease and growth. Phytopathology 77, 393-8.

Zadoks JC, Chang TT, Konzak CF, 1974. A decimal code for the growth stages of cereals. Weed Research 14, 415-21.

Zadoks JC, Schein RD, 1979. Epidemiology and Plant Disease Management. New York, USA: Oxford University Press.

Ziv O, Eyal Z, 1976. Evaluation of tolerance to septoria leaf blotch in spring wheat. Phytopathology 66, 485-8.

Ziv O, Eyal Z, 1978. Assessment of yield component losses caused in plants of spring wheat cultivars by selected isolates of Septoria tritici. Phytopathology 68, 791-6.

Zuckerman E, Eshel A, Eyal Z, 1997. Physiological aspects related to tolerance of spring wheat cultivars to Septoria tritici blotch. Phytopathology 87, 60-5. 